\title{
A aplicação tópica de fluoretos deve ser precedida por profilaxia dos dentes
}

O controle das lesões de cárie ainda é uma questão muito importante na Odontologia, pois elas surgem em regiões onde a remoção do biofilme é difícil. Assim, se métodos químicos de proteção e controle da cárie, tal como a utilização de fluoretos, tivessem a capacidade de penetrar no biofilme, o potencial protetor desse método seria aumentado. Pesquisadores do Reino Unido hipotetizaram que a aplicação tópica de fluoretos tem a capacidade de penetrar nesses depósitos e apresentaram os resultados de seu estudo no exemplar de maio desse ano do Journal of Dental Research*. Inicialmente, eles expuseram biofilmes gerados in vivo que estavam depositados sobre superfícies naturais de esmalte ao $\mathrm{NaF}$ (1000 ppm F-) por períodos de 30 ou 120 segundos (o que é equivalente, aproximadamente, à exposição durante a escovação), ou 30 minutos. Os biofilmes foram cortados no sentido de sua profundidade e a concentração de fluoretos nas diferentes camadas foi medida com o uso de um eletrodo. Os resultados desse trabalho foram que as exposições de 30 e 120 segundos aumentaram a concentração de fluoretos no biofilme. Entretanto, essa concentração estava aumenta- da apenas nas porções mais superficiais do depósito, em contato com a saliva. Os biofilmes que foram expostos por um tempo mais prolongado ao fluoreto apresentaram concentrações aumentadas dessa substância junto à superfície dentária. A conclusão do trabalho é que a penetração de fluoretos no biofilme durante a aplicação tópica dessa substância é restrita e que isso pode limitar a eficácia de sua ação anti-cárie. Essa descoberta tem grande relevância para a Ortodontia. Pois os aparelhos ortodônticos, especialmente os fixos, agregam aos dentes muitas áreas de limpeza difícil. É importante que o profissional e o paciente estejam cientes que aplicações tópicas de flúor em dentes com acúmulo de biofilme tem uma ação muito restrita nas áreas cobertas pelo depósito. A conduta clínica correta é que aplicações tópicas de fluoretos sejam precedidas por uma profilaxia, para que as regiões mais susceptiveis à cárie sejam protegidas.

* WATSON, P.S.; et al. Penetration of Fluoride into Natural Plaque Biofilms. J Dent Res, v. 84, n. 5, p. 451-455, 2005.

\section{Lesões de cárie em dentes decíduos estão associadas a defeitos de formação do esmalte dos sucessores permanentes}

Defeitos de esmalte nos dentes permanentes têm ganhado mais atenção nos últimos anos. Por exemplo, muitos defeitos que talvez fossem considerados como manifestação da fluorose no passado, hoje são compreendidos como um fenótipo brando de amelogênese imperfeita. Alguns conceitos empíricos também têm sido revisados, como a noção que lesões de cárie nos dentes decíduos causam defeitos de desenvolvimento de esmalte nos dentes permanentes. Esta hipótese foi testada por um grupo de pesquisadores da Nova Zelândia e publicado na edição de abril da revista mais importante da área odontológica, o Journal of Dental Research**. Os autores realizaram um estudo coorte prospectivo no qual foram avaliados os incisivos superiores de 663 crianças com idade de cinco anos e foi registrada a existência de lesões de cárie ou restaurações. As mesmas crianças foram reavaliadas à idade de nove anos em busca de defeitos de desenvolvimento de esmalte. Os da- dos foram ajustados para o gênero do indivíduo, estatus sócio-econômico da família, anos de exposição à água fluoretada, trauma e perda precoce dos dentes decíduos. Seus resultados demonstraram que o simples fato de ter havido uma lesão de cárie no dente decíduo acarreta em um aumento em mais de duas vezes na chance de ocorrer uma alteração na formação do esmalte. Essas alterações, quase sempre, se manifestam como opacidades no esmalte dos sucessores permanentes. Esse dado traz uma luz adicional às causas dos defeitos de desenvolvimento do esmalte e pode ser utilizado para responder a uma questão muito freqüente em nossos consultórios: "Doutor, por que minha filha tem essa mancha no dente da frente?"

** BROADBENT, J.M.; THOMSON, W.M.; WILLIAMS, S.M. Does Caries in Primary Teeth Predict Enamel Defects in Permanent Teeth? A Longitudinal Study. J Dent Res, v. 84, n. 3, p. 260-264, 2005.

Essa seção é realizada pelo Dr. Jorge Faber, Doutor em Biologia Animal, Laboratório de Microscopia Eletrônica - UnB e Mestre em Ortodontia - UFRJ (jorgefaber@terra.com.br). Envie suas sugestões e opiniões para o e-mail dental@dentalpress.com.br. 